\title{
Ring opening of 2-aza-3-borabicyclo[2.2.0]hex-5-ene, the Dewar form of 1,2-dihydro-1,2-azaborine: stepwise versus concerted mechanisms
}

\author{
Holger F. Bettinger ${ }^{*}$ and Otto Hauler
}

\author{
Full Research Paper \\ Address: \\ Institut für Organische Chemie, Universität Tübingen, Auf der \\ Morgenstelle 18, 72072 Tübingen, Germany

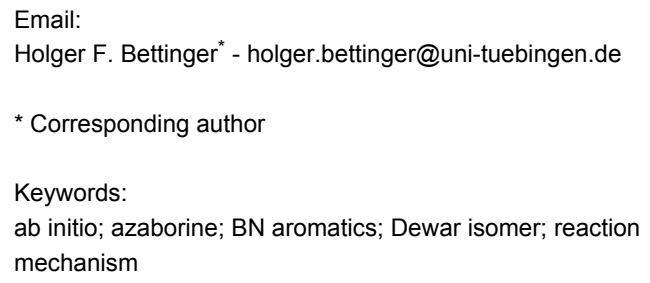

\author{
Beilstein J. Org. Chem. 2013, 9, 761-766. \\ doi:10.3762/bjoc.9.86 \\ Received: 12 February 2013 \\ Accepted: 21 March 2013 \\ Published: 18 April 2013 \\ This article is part of the Thematic Series "New reactive intermediates in \\ organic chemistry". \\ Guest Editor: G. Bucher
}

(C) 2013 Bettinger and Hauler; licensee Beilstein-Institut.

License and terms: see end of document.

\begin{abstract}
The ring opening of the Dewar form of 1,2-dihydro-1,2-azaborine, 2-aza-3-borabicyclo[2.2.0]hex-5-ene (3) is investigated by theoretical methods by using multiconfiguration SCF (CASSCF) and coupled cluster theory [CCSD(T)] with basis sets up to polarised quadruple-zeta quality. The title compound was previously reported to form photochemically in cryogenic noble gas matrices from 1,2-dihydro-1,2-azaborine (4). Four reaction paths for the thermal ring opening of $\mathbf{3}$ to $\mathbf{4}$ could be identified. These are the conventional disrotatory and conrotatory electrocyclic ring-opening pathways where the BN unit is only a bystander. Two more favourable paths are stepwise and involve 1,3-boron-carbon interactions. The lowest energy barrier for the isomerisation reaction, $22 \mathrm{kcal} \mathrm{mol}^{-1}$, should be high enough for an experimental observation in solution. However, in solution the dimerisation of $\mathbf{3}$ is computed to have a very low barrier $\left(3 \mathrm{kcal} \mathrm{mol}^{-1}\right)$, and thus 3 is expected to be a short-lived reactive intermediate.
\end{abstract}

\section{Introduction}

The barrier for ring opening of Dewar benzene (1) to yield benzene (2) is high enough to give this benzene valence isomer a half life of about two days [1] at room temperature despite the significant exothermicity $\left(60-70 \mathrm{kcal} \mathrm{mol}^{-1}\right)$ of the isomerisation reaction (Scheme 1) [2-6]. The relatively high barrier $\left(\Delta H^{*}\right.$ $\left.=25.1 \pm 2 \mathrm{kcal} \mathrm{mol}^{-1}\right)[7,8]$ is due to the fact that the formation of benzene from 1 would require a disrotatory ring opening that is orbital-symmetry-forbidden according to the Woodward-Hoffmann rules [9-11]. The allowed conrotatory electrocyclic opening of one of the cyclobutene moieties of $\mathbf{1}$, on the other hand, would result in a highly strained cis,cis,transcyclohexa-1,3,5-triene (trans-benzene) isomer [10,11].

Computational investigations of the isomerisation have been performed to reveal mechanistic details [12-14]. The most sophisticated investigation [14] (multireference configuration interaction, energies based on complete active space self-consistent field geometries, MRCI//CASSCF) confirmed an earlier conclu- 


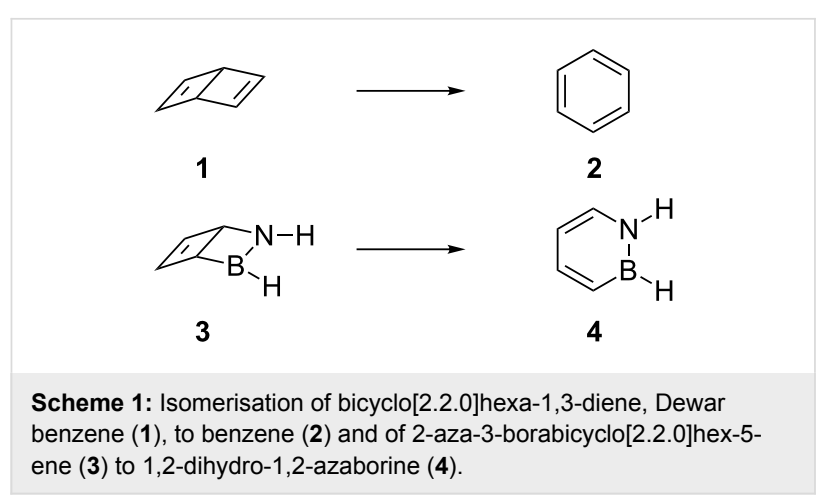

sion [13] that the conrotatory motion is the lowest energy pathway. It was also demonstrated that the conrotatory transition structure connects $\mathbf{1}$ and benzene directly, i.e., without the involvement of trans-benzene [14]. The barrier computed $\left(32.6 \mathrm{kcal} \mathrm{mol}^{-1}\right)$ is lower than that for the disrotatory pathway by $6.6 \mathrm{kcal} \mathrm{mol}^{-1}[14]$.

We have recently reported that the irradiation $(\lambda=254 \mathrm{~nm})$ of 1,2-dihydro-1,2-azaborine (4), a boron-nitrogen heterocycle that is isoelectronic and isosteric with benzene [15], results in its Dewar isomer 2-aza-3-borabicyclo[2.2.0]hex-5-ene (3) under the conditions of cryogenic noble gas matrix isolation [16]. Under these experimental conditions $(T<35 \mathrm{~K})$, the isomerisation back to 4 is not observed [16]. Can 3 exist outside of cryogenic matrices? To answer this question, we report here a computational investigation of important intramolecular and intermolecular decomposition pathways of $\mathbf{3}$.

\section{Results and Discussion Ring opening of $\mathbf{3}$ \\ Conrotatory and disrotatory ring opening}

We have performed explorative computations using the CASSCF $(6,6) / 6-31 \mathrm{G}^{*}$ method and could locate transition states for the conrotatory (TS1; $n_{\mathrm{imag}}=1, i 556 \mathrm{~cm}^{-1}$ ) and disrotatory (TS2; $n_{\mathrm{imag}}=1, i 628 \mathrm{~cm}^{-1}$ ) ring opening of 3 . Computation of the intrinsic reaction coordinates confirms that both TS1 and TS2 connect the Dewar form 3 to 1,2-dihydro-1,2-azaborine. These transition states are similar in geometry to those described earlier for the all-carbon system (see Figure 1 and Figure 2) [14]. The C1-C4 distance is shorter in TS1 (2.247 $\AA$ ) than it is in TS2 (2.313 $\AA$ ). The BN unit is a bystander in these two mechanisms as it is not involved in the ring-opening process.

The energies of these transition states were refined with multireference perturbation theory (MRMP2). In agreement with the results obtained for the all-carbon system [14], the barrier for the orbital-symmetry-allowed conrotatory ring opening is lower $\left(26.5 \mathrm{kcal} \mathrm{mol}^{-1}\right)$ than it is for the forbidden

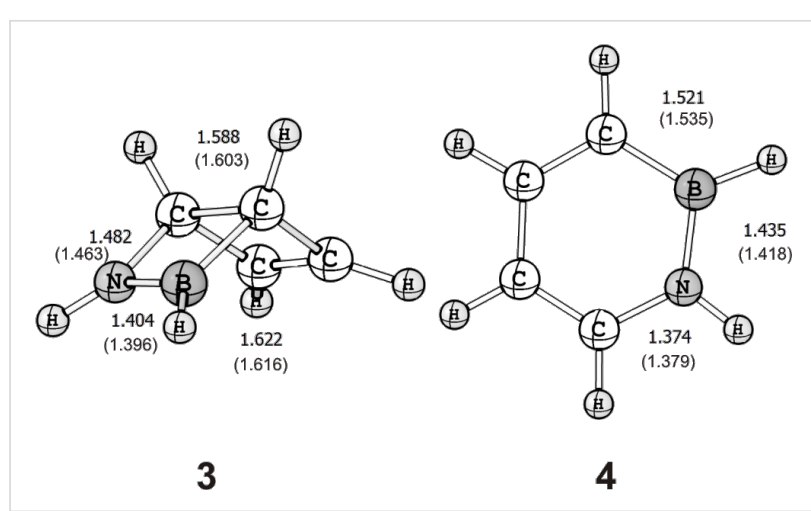

Figure 1: Geometries of 3 and 4 computed at the $\operatorname{CCSD}(T) / T Z 2 P$ and $\operatorname{CASSCF}(6,6) / 6-31 G^{*}$ (in parentheses) levels of theory. Bond lengths are given in angstroms $(\AA)$.

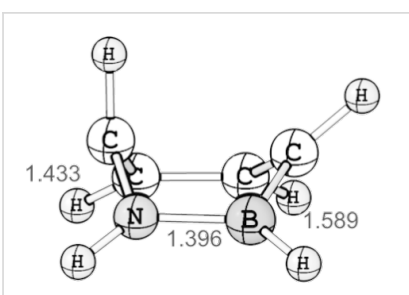

C1-C4: 2.247

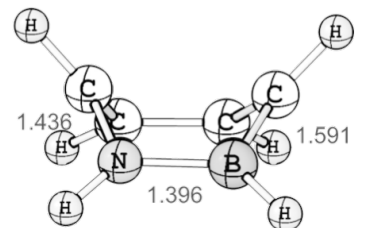

C1-C4: 2.313
Figure 2: Geometries of TS1 and TS2 computed at the $\operatorname{CASSCF}(6,6) /$ 6-31G* level of theory. C1-N, N-B, C4-B, and C1-C4 distances are given in angstroms $(\AA)$.

disrotatory reaction $\left(30.1 \mathrm{kcal} \mathrm{mol}^{-1}\right)$ (Table 1). The energy difference of about $4 \mathrm{kcal} \mathrm{mol}^{-1}$ is slightly smaller than that reported for the all-carbon system $\left(7 \mathrm{kcal} \mathrm{mol}^{-1}\right)$ [14]. Due to the use of different levels of theory (MRMP2 in the present work, MRCI by Havenith et al. [14]), the energy barriers for conrotatory ring opening of $\mathbf{1}$ and $\mathbf{3}$ cannot be directly compared. We have made no attempt to increase the level of theory for TS1 and TS2 beyond MRMP2, because we found two additional reaction paths that are significantly more favourable.

\section{Stepwise ring opening}

Two additional pathways, both of them stepwise, for the ring opening of 3 could be identified. As the energies for the two reactions paths are very similar, we used coupled-cluster theory to obtain highly accurate structures (see Figure 3) and energies of the stationary points involved in ring opening. The $\operatorname{CCSD}(\mathrm{T})$ geometry optimizations arrive at a minimum on the potentialenergy surface (MIN1). Characteristic of this intermediate MIN1 is a short B-C1 distance of $1.858 \AA$, while the $\mathrm{C} 1-\mathrm{C} 4$ distance is increased to $2.318 \AA$. The nitrogen atom is strongly pyramidalised resulting in an $\mathrm{H}-\mathrm{N}-\mathrm{C} 1-\mathrm{H}$ dihedral angle of $175.2^{\circ}$. A second minimum MIN2 between 3 and 1,2-dihydro- 
Table 1: Relative energies ( $E_{\text {rel, }}$ in $\mathrm{kcal} \mathrm{mol}^{-1}$ including zero-point vibrational energies, ZPVE) of 1,2-dihydro-1,2-azaborine (4), its Dewar valence isomer 3 , high energy minima, and the transition states for ring opening of 3 as computed at the MRMP2 and $\operatorname{CCSD}(T)$ levels of theory.

\begin{tabular}{lcc} 
Compounds & $E_{\text {rel }}(\mathrm{MRMP} 2)^{\mathrm{a}}$ & $E_{\mathrm{rel}}(\mathrm{CCSD}(\mathrm{T}))^{\mathrm{b}}$ \\
\hline $\mathbf{3}$ & 0 & 0 \\
$\mathbf{4}$ & & -59.3 \\
TS1 (conrotatory) & 26.5 & $31.0^{\mathrm{c}}$ \\
TS2 (disrotatory) & 30.1 & - \\
MIN1 & - & 20.3 \\
TS3 & - & 21.7 \\
TS4 & - & 25.8 \\
MIN2 & --- & 17.8 \\
TS5 & - & 19.1 \\
TS6 & - & 22.2 \\
\hline
\end{tabular}

aMRMP2-CASSCF $(6,6) / 6-31 G^{*} / / \operatorname{CASSCF}(6,6) / 6-31 \mathrm{G}^{*}$, ZPVE were obtained at CASSCF $(6,6) / 6-31 \mathrm{G}^{*} ;{ }^{\mathrm{b}} \mathrm{CCSD}(\mathrm{T}) / \mathrm{cc}-\mathrm{pVQZ} / / \mathrm{CCSD}(\mathrm{T}) /$ TZ2P, ZPVE were obtained at CCSD(T)/DZP; c CCSD(T)/cc-pVQZ based on $\operatorname{CASSCF}(6,6) / 6-31 G^{*}+Z P V E$ data for TS1 and 3 .

1,2-azaborine could also be located with the $\operatorname{CCSD}(\mathrm{T})$ method. The structure of MIN2 is characterised by an almost ecliptic orientation of the $\mathrm{N}-\mathrm{H}$ and $\mathrm{C} 1-\mathrm{H}$ bonds as the dihedral angle is only $7.8^{\circ}$. The $\mathrm{B}-\mathrm{C} 1$ distance of $1.827 \AA$ is slightly shorter while the $\mathrm{C} 1-\mathrm{C} 4$ distance of $2.336 \AA$ is slightly longer than in
MIN1. Hence MIN1 and MIN2 mainly differ by the relative orientation of the $\mathrm{N}-\mathrm{H}$ bond. The strong pyramidalisation of the nitrogen atom and the short $\mathrm{B}-\mathrm{C} 1$ distance show that in these two reaction pathways the $\mathrm{BN}$ unit is no longer just a bystander. The mode of rotation that results in MIN1 and MIN2 may be considered conrotatory, but the $\mathrm{C} 4 \mathrm{H}$ group has moved significantly more than the $\mathrm{C} 1 \mathrm{H}$ group. The electron pair of the breaking $\mathrm{C} 1-\mathrm{C} 4$ bond is utilized for interaction with the boron centre. As a consequence, the nitrogen lone pair is more localised resulting in a pyramidalisation of the nitrogen centre.

At our highest level of theory, $\operatorname{CCSD}(\mathrm{T}) / \mathrm{cc}-\mathrm{pVQZ}, \mathbf{M I N 2}$ is more stable than MIN1 by $2.5 \mathrm{kcal} \mathrm{mol}^{-1}$. MIN2 is $17.8 \mathrm{kcal} \mathrm{mol}^{-1}$ higher in energy than the Dewar form. Both MIN1 and MIN2 correspond to shallow minima on the potential energy surface. The barrier for collapse of MIN1 to the Dewar form 3 through transition state TS3 is only $1.4 \mathrm{kcal} \mathrm{mol}^{-1}$, while formation of 1,2-dihydro-1,2-azaborine from MIN1 through TS4 has a barrier of $5.5 \mathrm{kcal} \mathrm{mol}^{-1}$. Likewise, collapse of MIN2 to the Dewar form 3 via TS5 has a barrier of only $1.3 \mathrm{kcal} \mathrm{mol}^{-1}$, and formation of 1,2-dihydro1,2-azaborine through TS6 has a barrier of $4.4 \mathrm{kcal} \mathrm{mol}^{-1}$.

For most of the stationary points the $\mathrm{T}_{1}$ diagnostic [17], a measure of the reliability of single-reference based $\operatorname{CCSD}(\mathrm{T})$ theory, is below the critical value of 0.02 indicating that the

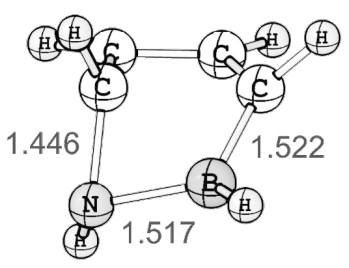

$$
\begin{gathered}
\text { C1-C4: } 1.916 \\
\text { C1-B: } 1.838
\end{gathered}
$$

TS3

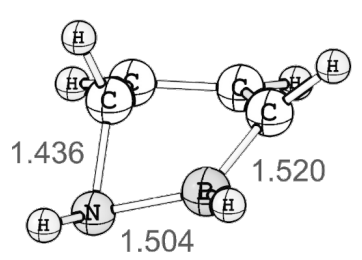

$$
\begin{gathered}
\text { C1-C4: } 1.983 \\
\text { C1-B: } 1.823
\end{gathered}
$$

TS5

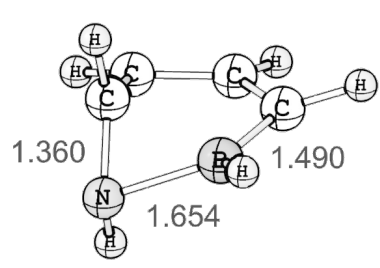

$$
\begin{gathered}
\text { C1-C4: } 2.318 \\
\text { C1-B: } 1.858
\end{gathered}
$$

MIN1

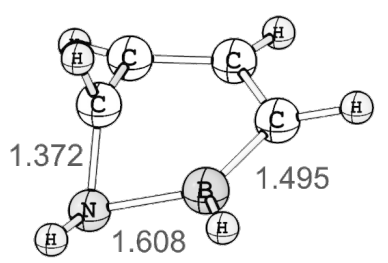

$$
\begin{aligned}
& \text { C1-C4: } 2.336 \\
& \text { C1-B: } 1.827
\end{aligned}
$$

MIN2

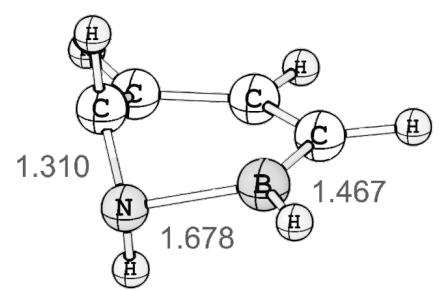

\section{C1-C4: 2.546}

C1-B: 2.296

TS4

Figure 3: Geometries of MIN1, TS3, TS4 and MIN2, TS5, TS6 computed at the CCSD(T)/TZ2P level of theory. C1-N, N-B, C4-B, C1-C4, and C1-B distances are given in angstroms $(\AA)$. 
$\mathrm{CCSD}(\mathrm{T})$ treatment should produce highly reliable results. Only for TS4 and TS6 are the $T_{1}$ diagnostics 0.024 and 0.023 , respectively. To confirm that the single reference $\operatorname{CCSD}(\mathrm{T})$ treatment produces satisfactory results also for these stationary points, we have computed the completely renormalised CR-CCSD $(\mathrm{T}) \mathrm{L}$ energies for all species, as $\mathrm{CR}-\mathrm{CCSD}(\mathrm{T}) \mathrm{L}$ has been shown to dramatically improve $\operatorname{CCSD}(\mathrm{T})$ results of multireference cases. The CR-CCSD $(\mathrm{T}) \mathrm{L}$ energies are within $0.2 \mathrm{kcal} \mathrm{mol}^{-1}$ of the $\operatorname{CCSD}(\mathrm{T})$ values for all these species, including those (TS4 and TS6) with slightly elevated $\mathrm{T}_{1}$ diagnostics.

Comparison of the energies of the stationary points along the stepwise pathways with TS1 and TS2 is hampered by problems associated with locating the latter at the $\operatorname{CCSD}(\mathrm{T})$ level. We have thus computed the barrier for conrotatory ring opening at the $\operatorname{CCSD}(\mathrm{T})$ and $\mathrm{CR}-\mathrm{CCSD}(\mathrm{T})$ levels using the $\operatorname{CASSCF}(6,6)$ geometries. This shows that the stepwise mechanism is more favourable than the conrotatory opening by $9 \mathrm{kcal} \mathrm{mol}^{-1}$.

In summary, the energetically most favourable pathway for the ring opening of 3 to 1,2-dihydro-1,2-azaborine involves MIN2 as a shallow intermediate and has a highest energy barrier of $22 \mathrm{kcal} \mathrm{mol}^{-1}$. This is roughly $10 \mathrm{kcal} \mathrm{mol}^{-1}$ lower than the lowest energy pathway for ring opening of Dewar benzene.
Therefore, the lifetime of the Dewar form $\mathbf{3}$ is expected to be significantly lower than that of Dewar benzene. Nonetheless, with a barrier for isomerisation of about $22 \mathrm{kcal} \mathrm{mol}^{-1}, \mathbf{3}$ should be observable in solution.

\section{Dimerisation of 3}

Alternative pathways for disappearance of $\mathbf{3}$ may be provided by intermolecular reactions that are in principle feasible in solution. Such pathways are of particular importance, as the $\mathrm{BN}$ unit in $\mathbf{3}$ is an aminoborane ( $\mathrm{RHB}=\mathrm{NHR}$ ) derivative. Aminoboranes with small substituents are unstable with respect to dimerisation or oligomerisation. In 1,2-dihydro-1,2-azaborine, such a dimerisation is not observed, probably due to the aromatic character of the six-membered ring. In $\mathbf{3}$, however, this aromatic stabilisation is no longer available.

For the sake of simplicity, we only considered dimers of $\mathbf{3}$ (see Figure 4 and Supporting Information File 1 for structures). All three diastereomeric dimers of $\mathbf{3}$ are thermodynamically more stable than two noninteracting monomers. Formation of the most stable dimer, DIM1, is favourable by $37 \mathrm{kcal} \mathrm{mol}^{-1}$. The barrier for its formation at the SCS-RIMP2/def2-TZVP level of theory is only $3.4 \mathrm{kcal} \mathrm{mol}^{-1}$ with respect to infinitely separated monomers, and $5.6 \mathrm{kcal} \mathrm{mol}^{-1}$ with respect to the energy of a van-der-Waals complex of two monomers.

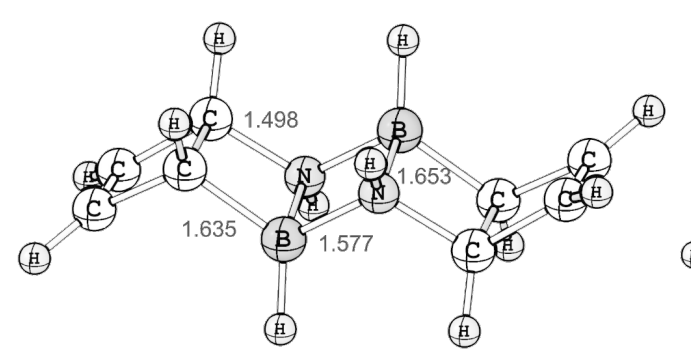

DIM1 $\left(C_{\mathrm{i}}\right),-37.0$

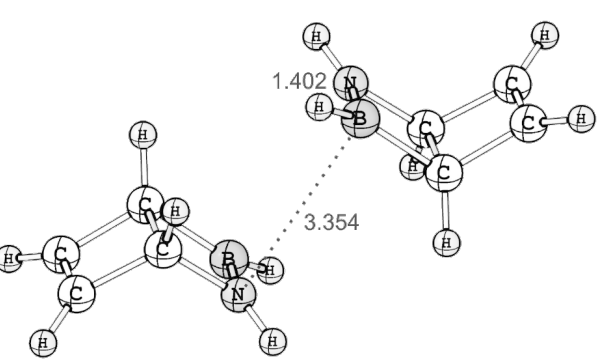

$\operatorname{COM1}\left(C_{i}\right),-2.2$

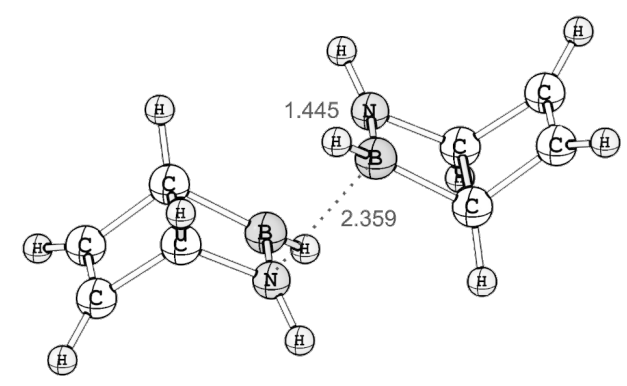

$\operatorname{TS} 7\left(C_{\mathrm{i}}\right),+3.4$

Figure 4: Geometries of DIM1, COM1, and TS7 computed at the SCS-RIMP2/def2-TZVP level of theory. Distances are given in angstroms ( $\AA$ ). Energies (in kcal mol${ }^{-1}$ ) relative to two separated molecules of $\mathbf{3}$ were obtained at the same level of theory and include ZPVE corrections obtained with the smaller def-SV(P) basis set. 


\section{Conclusion}

The following conclusions can be drawn from the computational investigation.

1. The "classical" conrotatory and disrotatory ring-opening reactions provide pathways for the isomerisation of 3 to $1,2-$ dihydro-1,2-azaborine. Similar to previous investigations of the ring opening of Dewar benzene (1), we find that the conrotatory pathway is lower in energy than the orbital-symmetryforbidden disrotatory pathway. Both pathways are concerted.

2. In addition, two step-wise pathways that involve conformational isomeric minima were identified. Both of the minima have in common short 1,3-transannular $\mathrm{C}-\mathrm{B}$ distances. The two pathways have very similar energy barriers (within $4 \mathrm{kcal} \mathrm{mol}^{-1}$ ). The more favourable one is lower in energy than the conrotatory ring opening by $9 \mathrm{kcal} \mathrm{mol}^{-1}$.

3. The lowest energy pathway for ring opening of $\mathbf{3}$ has a barrier of $22 \mathrm{kcal} \mathrm{mol}^{-1}$.

4. The lifetime of $\mathbf{3}$ in solution will not be limited by the ring opening to 4 , but rather by dimerisation. This is a strongly exothermic process that has a low barrier of $3 \mathrm{kcal} \mathrm{mol}^{-1}$ with respect to separated monomers. Thus, $\mathbf{3}$ is expected to be a highly reactive compound that will rapidly undergo dimerisation (or oligomerisation) reactions.

\section{Experimental}

The active space in the $\operatorname{CASSCF}(6,6)$ computations included the $\pi$ and $\pi^{*}$ orbitals for the 1,2-dihydro-1,2-azaborine system, while the four $\pi$ and $\pi^{*}$ orbitals along with the $\mathrm{C} 3-\mathrm{C} 6 \sigma / \sigma^{*}$ orbitals were used for the Dewar form 3 and transition states TS1 and TS2. Geometries were fully optimised and the nature of stationary points was confirmed by analytic computation of second derivatives. Intrinsic reaction coordinates were computed starting from the transition states by using the Schlegel-Gonzalez algorithm $[18,19]$. The same $(6,6)$ active space was employed for the subsequent multireference secondorder perturbation theory (MRMP2) [20] single-point-energy computations. All multireference computations employed the 6-31G* [21] basis set and were performed with the Gamess-US software [22].

The coupled-cluster method with single, double, and a perturbative estimate of triple excitations [CCSD(T)] [23] was employed for geometry optimisation by using analytic gradients [24] in conjunction with Dunning's [25,26] DZP and TZ2P basis sets. Harmonic vibrational frequencies were computed by analytic second derivatives [27] using the DZP basis set to confirm the nature of stationary points and to obtain zero-point vibrational energies (ZPVE). The $\operatorname{CCSD}(\mathrm{T})$ gradient and Hessian computations were performed with CFOUR [28]. The $\operatorname{CCSD}(\mathrm{T}) / \mathrm{TZ2P}$ geometries were used for further energy refinement with Dunning's [29] correlation consistent basis sets, cc-pVDZ, cc-pVTZ, and cc-pVQZ. These single point calculations were performed with the Turbomole program [30]. Its implementation of CCSD(T) uses integral-direct techniques and the resolution-of-the-identity approximation [31]. Therefore, the appropriate fitting basis set was chosen [32]. In addition, the so-called rigorously size-extensive completely renormalised coupled-cluster theory [CR-CC $(2,3)$ or CR-CCSD(T)L] $[33,34]$ was used in conjunction with the cc-pVDZ basis set using Gamess-US. The dimerisation of $\mathbf{3}$ was investigated by using Grimme's spin-component-scaled MP2 method (SCS-MP2) [35], with the resolution-of-identity (RI) approximation for fast computations of two-electron integrals within the second-order Møller-Plesset perturbation theory (MP2) [36,37]. SCS-MP2 was shown recently to yield improved interaction energies compared to conventional MP2 [38-41]. The def-SV(P) [B/C/N: 3s2p1d; H: 2s] [42] and def2-TVZP [B/C/N: 5s3p2d1f; H: $4 \mathrm{~s} 2 \mathrm{p} 1 \mathrm{~d}]$ [37] basis sets in conjunction with the corresponding fitting bases were employed [37]. Harmonic vibrational frequencies were determined by using the def-SV(P) basis set by finite differences of analytic gradients and provided the zeropoint vibrational energies (ZVPE).

\section{Supporting Information}

\section{Supporting Information File 1}

Additional data.

[http://www.beilstein-journals.org/bjoc/content/ supplementary/1860-5397-9-86-S1.pdf]

\section{Acknowledgements}

This work was supported by the Deutsche Forschungsgemeinschaft and Fonds der chemischen Industrie.

\section{References}

1. van Tamelen, E. E.; Pappas, S. P. J. Am. Chem. Soc. 1963, 85 , 3297-3298. doi:10.1021/ja00903a056

2. Volger, H. C.; Hogeveen, H. Recl. Trav. Chim. Pays-Bas 1967, 86, 830-832. doi:10.1002/recl.19670860806

3. Oth, J. F. M. Recl. Trav. Chim. Pays-Bas 1968, 87, 1185-1195. doi:10.1002/recl.19680871012

4. Schäfer, W. Angew. Chem., Int. Ed. Engl. 1966, 5, 669. doi:10.1002/anie.196606691

5. Adam, W.; Chang, J. C. Int. J. Chem. Kinet. 1969, 1, 487-492. doi:10.1002/kin.550010509

6. Oth, J. F. M. Angew. Chem., Int. Ed. Engl. 1968, 7, 646.

7. Breslow, R.; Napierski, J.; Schmidt, A. H. J. Am. Chem. Soc. 1972, 94, 5906-5907. doi:10.1021/ja00771a068 
8. Lechkten, P.; Breslow, R.; Schmidt, A. H.; Turro, N. J. J. Am. Chem. Soc. 1973, 95, 3025-3027. doi:10.1021/ja00790a054

9. Woodward, R. B.; Hoffmann, R. Angew. Chem. 1969, 81, 797-869. doi:10.1002/ange.19690812102

10. van Tamelen, E. E. Angew. Chem., Int. Ed. Engl. 1965, 4, 738-745. doi:10.1002/anie.196507381

11. van Tamelen, E. E. Acc. Chem. Res. 1972, 5, 186-192. doi:10.1021/ar50053a004

12. Dewar, M. J. S.; Ford, G. P.; Rzepa, H. S. J. Chem. Soc., Chem. Commun. 1977, 728-730. doi:10.1039/C39770000728

13. Johnson, R. P.; Daoust, K. J. J. Am. Chem. Soc. 1996, 118, 7381-7385. doi:10.1021/ja961066q

14. Havenith, R. W. A.; Jenneskens, L. W.; van Lenthe, J. H. J. Mol. Struct.: THEOCHEM 1999, 492, 217-224. doi:10.1016/S0166-1280(99)00166-9

15. Marwitz, A. J. V.; Matus, M. H.; Zakharov, L. N.; Dixon, D. A.; Liu, S.-Y. Angew. Chem., Int. Ed. 2009, 48, 973-977. doi:10.1002/anie.200805554

16. Brough, S. A.; Lamm, A. N.; Liu, S.-Y.; Bettinger, H. F. Angew. Chem., Int. Ed. 2012, 51, 10880-10883. doi:10.1002/anie.201203546

17. Lee, T. J.; Taylor, P. R. Int. J. Quantum Chem., Quantum Chem. Symp. 1989, 36 (Suppl. S23), 199-207. doi:10.1002/qua.560360824

18. Gonzalez, C.; Schlegel, H. B. J. Chem. Phys. 1989, 90, 2154-2161. doi:10.1063/1.456010

19. Gonzalez, C.; Schlegel, H. B. J. Phys. Chem. 1990, 94, 5523-5527. doi:10.1021/j100377a021

20. Hirao, K. Chem. Phys. Lett. 1993, 201, 59-66. doi:10.1016/0009-2614(93)85034-L

21. Hariharan, P. C.; Pople, J. A. Theor. Chim. Acta 1973, 28, 213-222. doi:10.1007/BF00533485

22. Schmidt, M. W.; Baldridge, K. K.; Boatz, J. A.; Elbert, S. T.; Gordon, M. S.; Jensen, J. H.; Koseki, S.; Matsunaga, N.; Nguyen, K. A.; Su, S.; Windus, T. L.; Dupuis, M.; Montgomery, J. A., Jr. J. Comput. Chem. 1993, 14, 1347-1363. doi:10.1002/jcc.540141112

23. Raghavachari, K.; Trucks, G. W.; Pople, J. A.; Head-Gordon, M. Chem. Phys. Lett. 1989, 157, 479-483. doi:10.1016/S0009-2614(89)87395-6

24. Scuseria, G. E. J. Chem. Phys. 1991, 94, 442-447. doi:10.1063/1.460359

25. Dunning, T. H. J. Chem. Phys. 1970, 53, 2823-2833. doi:10.1063/1.1674408

26. Dunning, T. H. J. Chem. Phys. 1971, 55, 716-723. doi:10.1063/1.1676139

27. Gauss, J.; Stanton, J. F. Chem. Phys. Lett. 1997, 276, 70-77. doi:10.1016/S0009-2614(97)88036-0

28. Stanton, J. F.; Gauss, J.; Harding, M. E.; Szalay, P. G. CFOUR, Coupled-Cluster techniques for Computational Chemistry, For the current version, see http://www.cfour.de

29. Dunning, T. H. J. Chem. Phys. 1989, 90, 1007-1023. doi:10.1063/1.456153

30. TURBOMOLE ,V6.4 2012, University of Karlsruhe and Forschungszentrum Karlsruhe $\mathrm{GmbH}$, 1989-2007, TURBOMOLE $\mathrm{GmbH}$, since 2007; available from http://www.turbomole.com

31. Hättig, C.; Weigend, F. J. Chem. Phys. 2000, 113, 5154-5161. doi:10.1063/1.1290013

32. Weigend, F.; Köhn, A.; Hättig, C. J. Chem. Phys. 2002, 116, 3175-3183. doi:10.1063/1.1445115
33. Piecuch, P.; Kucharski, S. A.; Kowalski, K.; Musial, M. Comput. Phys. Commun. 2002, 149, 71-96. doi:10.1016/S0010-4655(02)00598-2

34. Piecuch, P.; Wloch, M. J. Chem. Phys. 2005, 123, 224105. doi:10.1063/1.2137318

35. Grimme, S. J. Chem. Phys. 2003, 118, 9095-9102. doi:10.1063/1.1569242

36. Weigend, F.; Häser, M. Theor. Chem. Acc. 1997, 97, 331-340. doi:10.1007/s002140050269

37. Weigend, F.; Häser, M.; Patzelt, H.; Ahlrichs, R. Chem. Phys. Lett. 1998, 294, 143-152. doi:10.1016/S0009-2614(98)00862-8

38. Hill, J. G.; Platts, J. A.; Werner, H.-J. Phys. Chem. Chem. Phys. 2006, 8, 4072-4078. doi:10.1039/b608623c

39. Antony, J.; Grimme, S. J. Phys. Chem. A 2007, 111, 4862-4868. doi:10.1021/jp070589p

40. Takatani, T.; Sherrill, C. D. Phys. Chem. Chem. Phys. 2007, 9 , 6106-6114. doi:10.1039/b709669k

41. Bachorz, R. A.; Bischoff, F. A.; Höfener, S.; Klopper, W.; Ottiger, P.; Leist, R.; Frey, J. A.; Leutwyler, S. Phys. Chem. Chem. Phys. 2008, 10, 2758-2766. doi:10.1039/b718494h

42. Schäfer, A.; Horn, H.; Ahlrichs, R. J. Chem. Phys. 1992, 97, 2571-2577. doi:10.1063/1.463096

\section{License and Terms}

This is an Open Access article under the terms of the Creative Commons Attribution License (http://creativecommons.org/licenses/by/2.0), which permits unrestricted use, distribution, and reproduction in any medium, provided the original work is properly cited.

The license is subject to the Beilstein Journal of Organic Chemistry terms and conditions:

(http://www.beilstein-journals.org/bjoc)

The definitive version of this article is the electronic one which can be found at: doi:10.3762/bjoc. 9.86 